\title{
AiMT
}

Advances in Military Technology

Vol. 12, No. 2 (2017), pp. 185-193

ISSN 1802-2308, eISSN 2533-4123

DOI 10.3849/aimt.01169

\section{Evaluation Method of Frangible Bullets Frangibility}

\author{
J. Komenda*, X.S. Bui, R. Vítek and L. Jedlička \\ Faculty of Military Technology, University of Defence in Brno, Czech Republic
}

The manuscript was received on 9 December 2016 and was accepted after revision for publication on 13 October 2017.

\begin{abstract}
:
The article deals with the quantification of frangibility of the frangible bullets, which has high practical significance in evaluating the capability of a bullet to fragment upon impact on the target or obstacle and which allows comparison between the different types of the frangible bullets. In this article new original evaluation method of frangibility of frangible pistol bullets when hitting to the defined target is presented.
\end{abstract}

\section{Keywords:}

frangible ammunition, frangibility of bullet, quantification of frangibility, metal powder

\section{Introduction}

Terminal ballistics of frangible ammunition is very specific, especially the description of the ability of disintegration of a bullet into fragments of various sizes upon impact on the hard target. The ability to disintegrate, called frangibility of frangible bullet, depends on the various factors, mainly on the mechanical properties of bullet's material, the shape of bullet (FP, RN, HP), the design of bullet (the presence or absence of the jacket), the production technology (densification process, usage of binder, sintering), the impact conditions with the obstacle (impact velocity, angle of incidence), the type of the obstacles, etc. Disintegration of a standard compact frangible bullet usually occurs only when it hits a hard rigid obstacle. However, the bullets of high frangibility (called ultra-frangible bullets) can disintegrate even when they penetrate the soft tissues and their substitutions. Change in the manufacturing technology of frangible bullets can bring their very different capabilities to disintegrate under the same testing conditions.

Quantification of the frangible bullet's frangibility has high practical significance in evaluation of the capability of a bullet to fragment and in comparison of different types of frangible bullets. To evaluate the frangibility of frangible bullet, various theoretical and experimental methods which have not yet been on a global scale elaborated on at a required level can be used. In some laboratories a steel box is used into which the rounds are fired. The bullets strike on the angled steel plate and the fragments of the bullet are caught in water tank beneath the impact plate. Nevertheless, the frangibility

\footnotetext{
* Corresponding author: Department of Weapons and Ammunition, University of Defence in Brno, Kounicova 65, 66210 Brno. Phone: +420 9734436 20, e-mail: jan.komenda@unob.cz
} 
assessment strongly depends on the criteria which are set up for evaluating the results. For example, some agencies in USA believe that frangibility depends on the size of the fragments left after the impact; e.g. $X$ number of fragments of $Y$ size or larger and the round is noncompliant; $Z$ numbers of fragments of $W$ to $Y$ size, and the round is marginal, etc. [1]. In the Czech Republic, one of the published methods of evaluation of frangibility is also described in [2-4].

The theoretical evaluation of frangibility is more difficult and less reliable than the experimental one. Therefore, the experimental approach to the frangibility evaluation is preferable when the results of shooting on the selected standard target are used. Subsequently, the bullet's frangibility is evaluated and this evaluation is based on the size distribution of the fragments or on the damage level of the standard target. In this article, a new quantitative indicator of frangibility is presented, called Frangibility factor $\boldsymbol{F F}$ - either theoretical $\boldsymbol{F F}_{T}$ or experimental $\boldsymbol{F F}_{\boldsymbol{E}}$.

\section{Theoretical Evaluation of Frangibility Based on Impact Energy}

The theoretical evaluation of frangibility called the frangibility factor $F F_{T}$ is defined as a ratio between the kinetic impact energy $E_{\text {imp }}$ of bullet hitting the specific hard target and the bullet's lower limit impact energy $E_{l, \text { lim }}$ for this target:

$$
F F_{T}=\frac{E_{\text {imp }}}{E_{l, \lim }} .
$$

The frangibility factor $F F_{T}$ is defined for the standard hard target and for the perpendicular impact to the surface of the target. The impact kinetic energy of the bullet is determined by the following relation:

$$
E_{\mathrm{imp}}=\frac{1}{2} m_{q} v_{i m p}^{2},
$$

where $m_{q}$ is the mass of bullet and $v_{i m p}$ is the impact velocity of the bullet.

Lower limit impact kinetic energy of bullet is:

$$
E_{l, \lim }=\frac{1}{2} m_{q} v_{l, \lim }^{2}
$$

where: $v_{l, \text { lim }}$ is the lower limit impact velocity of bullet whose value for the particular bullet depends on the type of target; $v_{l, \text { lim }}$ is the theoretical maximal impact velocity of bullet on defined target at which the disintegration of bullet does not occur yet. However, the cracks can appear in the body of the bullet.

Lower limit velocity $v_{l, \text { lim }}$ can be expressed for a homogeneous frangible bullet hitting an elastic target by the following formula [2]:

$$
v_{l, \lim }=\frac{2 K \varepsilon_{x, \max }}{\rho l} \sqrt{m_{q}\left(\frac{4 l}{3 K \pi d^{2}}+\frac{1}{c}\right)},
$$

where $\varepsilon_{x, \max }$ - the maximal compressive strain of the bullet in the model of an ideal elastic material [-], $K-$ the modulus of elasticity in compression [Pa], $\rho$ - the density of the bullet $\left[\mathrm{kgm}^{-3}\right], l-$ the length of the bullet $[\mathrm{m}], m_{q}-$ the mass of the bullet $[\mathrm{kg}], d-$ the diameter of the bullet $[\mathrm{m}], c-$ the stiffness of the hard target $\left[\mathrm{Nm}^{-1}\right]$.

By this formula, the lower limit velocity of the bullet Sinterfire and SR have been calculated in [3] $69.4 \mathrm{~ms}^{-1}$ and $32.9 \mathrm{~ms}^{-1}$, respectively when it impacts on the target which is a steel plate with the diameter of $0.5 \mathrm{~m}$ and the thickness of $10 \mathrm{~mm}$. 
In the case of bullet's impact on an absolutely rigid target, the formula that has been presented in the literature [5] can be applied:

$$
v_{l, \lim }=\int_{0}^{\varepsilon_{\max }} \sqrt{\frac{\mathrm{d} \sigma / \mathrm{d} \varepsilon}{\rho}} \mathrm{d} \varepsilon,
$$

where $\varepsilon_{\max }$ is the limit (maximal) axial strain at which the material of the bullet is broken [-]; $\sigma$ is the compressive stress in bullet's material [Pa]; differential $\mathrm{d} \sigma / \mathrm{d} \varepsilon$ is obtained from the curve stress-strain of material, $\rho$ is the specific mass of the bullet $\left[\mathrm{kgm}^{-3}\right]$.

The frangibility factor $\left(F F_{T}\right)$ expresses the amount of impact energy of the bullet which is used for the disintegration of the bullet into fragments (particles), for the damage of the target and for the acceleration of the bullet fragments. If the value of $F F_{T}$ is lower than 1, the bullet does not fragment, and if it is greater than 1 the bullet fragments. The capability of the bullet to break into smaller fragments increases with increasing the value of $F F_{T}$.

Theoretically, beside the lower limit energy of bullet, also an upper limit impact energy can be used for the evaluation of the bullet's frangibility potential. While the lower limit impact energy is the highest energy at which there is no fundamental damage of bullet, the upper limit impact energy is the energy at which the bullet shatters into fragments of the same size as the grains of metal powder which have been used for the manufacture of the bullet. However, the upper limit impact energy is just a theoretical value. The real disintegration of the entire bullet into original grains in practice never happen.

Fig. 1 shows a typical relationship between the number of fragments produced by the disintegration of frangible bullet and the impact energy. At low impact energy, the disintegration of bullet does not occur. The bullet starts to disintegrate into fragments when the value of impact energy reaches the lower limit energy $E_{l, \text { lim. }}$. The number of fragments increases with increasing the impact energy of the bullet. At a high impact energy of bullet, the number of fragments approaches the value of $N_{0}$. In the high zone, above the upper limit value of energy, its progress is constant and the number of fragments equals the number of fragments $N_{0}$ (corresponding to the number of grains of powder which have been used for production of the bullet).

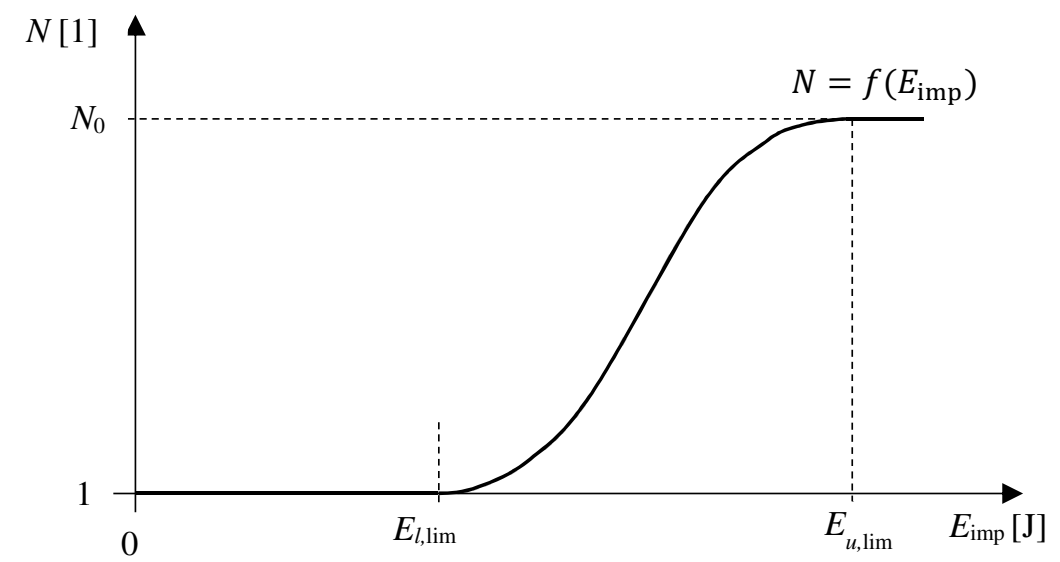

Fig. 1 Dependence of fragment number $N$ on impact energy $E_{\mathrm{imp}}$ of frangible bullet on obstacle [2] 
According to the Eq. (1), the frangibility factor $F F_{T}$ of frangible bullet is directly calculated from the impact and lower limit energy of bullet. This means that the $F F_{T}$ increases with increasing the impact energy of the bullet. However, when impact energy exceeds the upper limit energy (see Fig. 1), the number of fragments will not increase any more. In this case, the value of $F F_{T}$ is still growing, which does not correspond to reality. It is, therefore, more objective to establish the $F F_{T}$ using a logistic function in the form [6]:

$$
f(x)=\frac{L}{1+\mathrm{e}^{-k\left(x-x_{0}\right)}},
$$

where: $x_{0}$ - the $x$-value of the curve's midpoint; $L$ - the curve's maximum value; $k$ - the steepness of the curve.

With parameter $k=1$ and $x_{0}=0$, the value of the function is sufficient to compute for variable $x$ over a small range of real numbers, such as a range contained in $\langle-6,6\rangle$. But in fact, we can neglect a small difference in the boundary values, so we intend to take variable $x$ in the range of $\langle-5,5\rangle$. Now, we need to move the midpoint of the curve to have the positive value of variable $x$. So, $x_{0}=5$ is taken. To facilitate the numeral evaluation and unification with experimental evaluation of frangibility below, the maximum value $L=100$ is taken.

Finally, theoretical frangibility factor is established on the basis of the lower and the upper limit impact energy:

$$
F F_{T}=\frac{100}{1+\mathrm{e}^{-\left(f\left(E_{\mathrm{imp}}\right)-5\right)}}
$$

where:

$$
f\left(E_{\text {imp }}\right)=10 \sqrt{\frac{E_{\text {imp }}-E_{l, \lim }}{E_{u, \text { lim }}-E_{l, \mathrm{lim}}}} .
$$

The function $f\left(E_{\mathrm{imp}}\right)$ is defined by the Eq. (8) only for the values of the energy $E_{\text {imp }}$ within the range

$$
E_{l, \lim } \leq E_{\text {imp }} \leq E_{u, \lim } .
$$

Characteristic $F F_{T}$ is applied with the following contractual boundary conditions (neglecting differences about $0.7 \%$ between the real value of function $F F_{T}$ and theoretical limit value 0 and 100):

$$
\begin{gathered}
F F_{T}=0 \text { with } E_{\text {imp }}<E_{l, \lim }, \\
F F_{T}=100 \text { with } E_{\text {imp }}>E_{l, \lim } .
\end{gathered}
$$

The value of the lower limit impact energy of the frangible bullet can be determined either by theoretical calculations, or by experiment. To determine the theoretical lower and upper limit velocities of frangible bullet, an appropriate software, e.g. Ansys Autodyn, can be used. With appropriate meshing, the size of the smallest fragment of simulation can be determined, but it can be very different from the grain size of metal powder from which the bullet was made. Finer mesh represents a better behaviour of brittle material, but this significantly increases the computing time, especially when solving 3D tasks. The biggest problem of simulations is the absence of the material models for the real material of frangible bullets. 


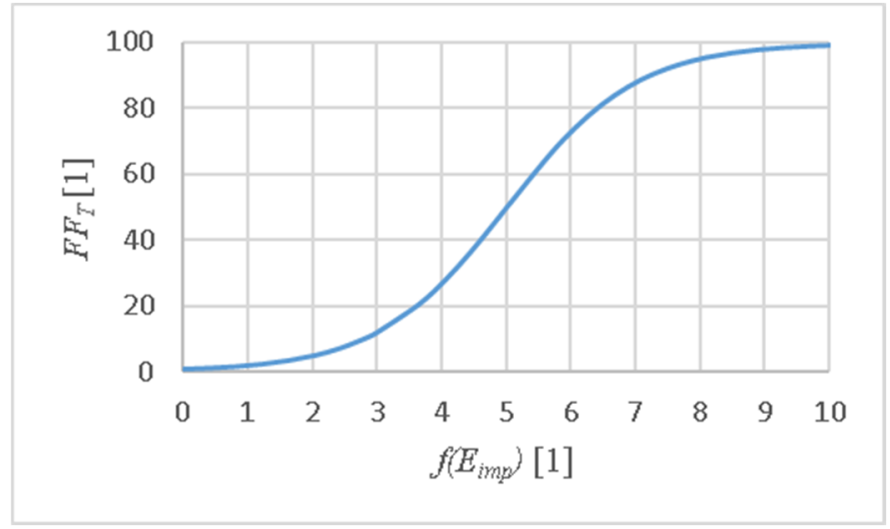

Fig. 2 Curve of proposed function $F F_{T}$ according to Eq. (7)

Although the value of the upper limit impact energy of bullet can be determined experimentally, it is rather difficult. The fragmentation of the bullet is affected by the deformation of the surface of the impacted obstacle. Furthermore, in case of certain impact kinetic energy, the shattering bullet is secondary compressed into a secondary fragment, as it can be seen in Fig. 3. At the high impact energy of bullet, the penetration of plate can occur even without complete or partial disintegration of the bullet. Conversely, the bullet may already fragment when firing, i.e. during the movement in the barrel, when the bullet is highly accelerated.

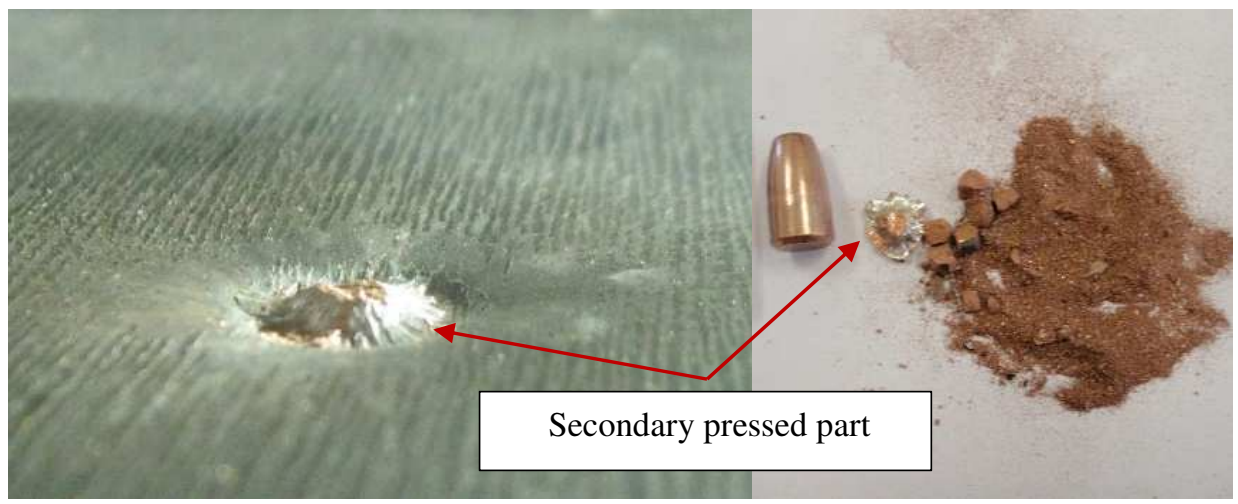

Fig. 3 Traces of frangible bullet Sinterfire $9 \mathrm{~mm}$ Luger on steel plate thickness of $5 \mathrm{~mm}$ (left) and its fragments (right)

\section{Experimental Evaluation of Frangibility Based on Size Distribution of Fragments by Shooting Experiment}

Analysis of size distribution of fragments is considered as the most widely used experimental method to evaluate frangibility of frangible bullet [1,2]. For shooting experiment, it is necessary to choose a suitable hard target on which the disintegration (fragmentation) of bullet should occur. The steel plate with a thickness from 4 to $10 \mathrm{~mm}$ is commonly chosen. A suitable trap is used to capture as many small fragments of the bullet as possible after hitting the target. The total mass of captured fragments compared 
to the original mass of bullet must be maximized (min. $90 \%$ ) to achieve sufficiently representative results of the evaluation of bullet's frangibility.

Captured fragments are divided into size classes of the individual fragments which are differentiated using sieves of defined mesh size. The frangibility factor may be determined according to the following equation [2]:

$$
F F_{E}=100 \sum_{i=1}^{n} K_{m i} \frac{m_{c i}}{m_{q}}[\%],
$$

where: $m_{c i}$ is the total mass of fragments in the particular size class $[\mathrm{kg}], m_{q}$ is the original mass of bullet $[\mathrm{kg}], K_{m i}$ is the size coefficient.

For each size class, the size coefficient $K_{m i}$ has been established which as the weighting number expresses the preference of the individual size classes of bullet's fragments. For the frangible bullet, the value of $K_{m i}$ is higher in the class which has the smaller size of fragments and vice versa.

Determining the frangibility factor according to the formula (8) is subjective because of the necessity of selecting the size coefficients. One of the subjective views, the below original model of the authors, is represented with five size classes based on the above formula for determining the frangibility factor in the form:

$$
F F_{E}=100\left(\frac{m_{c 1}}{m_{q}}+0.75 \frac{m_{c 2}}{m_{q}}+0.5 \frac{m_{c 3}}{m_{q}}+0.25 \frac{m_{c 4}}{m_{q}}+0.01 \frac{m_{c 5}}{m_{q}}\right),
$$

where $m_{c i}(i=1 \div 5)$ is the total mass of fragments in a particular size class whose limit sizes are defined according to Tab. 1 . The values of size coefficient $K_{m 1}=1, K_{m 2}=0.75$, $K_{m 3}=0.5, K_{m 4}=0.25$ a $K_{m 5}=0.01$ in the meaning of modified weighting numbers express the fact that the size class of fragments up to $0.5 \mathrm{~mm}$ has crucial importance for achieving the required high value of $F F_{E}$, while the meaning of the last size class of above $5 \mathrm{~mm}$ is negligible.

Tab. 1 Size classes of fragments

\begin{tabular}{|l|c|c|c|c|c|}
\hline $\begin{array}{l}\text { Size class of } \\
\text { fragments } \boldsymbol{i}\end{array}$ & 1 & 2 & 3 & 4 & 5 \\
\hline $\begin{array}{l}\text { Range of fragments } \\
\text { dimension [mm] }\end{array}$ & $(0,0.5\rangle$ & $(0.5,1\rangle$ & $(1,2\rangle$ & $(2,5\rangle$ & $\left(5, l_{q}\right\rangle$ \\
\hline
\end{tabular}

Note: $l_{q}$ - the length of bullet.

According to Eq. (9), the values of $F F_{E}$ in selected special cases are calculated and placed in the last row of Tab. 2. The boundary values of factor $F F_{E}$ are as following:

a) $F F_{E}=100 \%$ in the case when the bullet entirely disintegrates into fragments of the smallest size in the first class up to $0.5 \mathrm{~mm}$ (ideal result);

b) $F F_{E}=1 \%$ in the case when the bullet completely disintegrates into fragments of largest size in the last class above $5 \mathrm{~mm}$ (undesirable result);

c) $F F_{E}=0$ in the case when the bullet does not fragment after hitting the target (atypical result).

In the case of undesirable disintegration of bullet on the muzzle of the barrel or before hitting the target, the frangibility of the bullet is not evaluated. 
Tab. 2 Special values of factor $F F_{E}$ according to Eq. (9)

\begin{tabular}{|c|c|c|c|c|c|c|}
\hline \multirow{2}{*}{$\begin{array}{c}\text { Size } \\
\text { class of } \\
\text { fragments } \\
\boldsymbol{i}\end{array}$} & $\begin{array}{c}\text { Dimension } \\
\text { of } \\
\text { fragments } \\
{[\mathbf{m m}]}\end{array}$ & \multicolumn{5}{|c|}{ Special case of disintegration of bullet } \\
\cline { 3 - 7 } (values $\left.\frac{m_{c i}}{m_{q}}\right)$ \\
\hline 1 & $(0,0.5\rangle$ & $\mathbf{1}$ & 0 & 0 & 0 & 0 \\
\hline 2 & $(0.5,1\rangle$ & 0 & $\mathbf{1}$ & 0 & 0 & 0 \\
\hline 3 & $(1,2\rangle$ & 0 & 0 & $\mathbf{1}$ & 0 & 0 \\
\hline 4 & $(2,5\rangle$ & 0 & 0 & 0 & $\mathbf{1}$ & 0 \\
\hline 5 & $\left(5, l_{q}\right\rangle$ & 0 & 0 & 0 & 0 & $\mathbf{1}$ \\
\hline & $\boldsymbol{F F}_{E}$ & $\mathbf{1 0 0}$ & $\mathbf{7 5}$ & $\mathbf{5 0}$ & $\mathbf{2 5}$ & $\mathbf{1}$ \\
\hline
\end{tabular}

The example shown below in Tab. 3, the shooting experiments of three types of frangible bullet to the steel plate of the thickness of $5 \mathrm{~mm}$ are shown. After classification of fragments, the values of $F F_{E}$ have been calculated according to the presented model. These values are placed in the last column of the table.

Tab. 3 Results of shooting experiments to $5 \mathrm{~mm}$ steel plate

\begin{tabular}{|c|c|c|c|c|c|c|c|c|c|c|}
\hline \multirow{2}{*}{$\begin{array}{l}\text { Frangible } \\
\text { Cartridge }\end{array}$} & \multirow{2}{*}{$\begin{array}{c}\text { Velocity } \\
v_{2.5} \\
{\left[\mathrm{~ms}^{-1}\right]}\end{array}$} & \multirow{2}{*}{$\begin{array}{c}\begin{array}{c}\text { Mass of } \\
\text { bullet }\end{array} \\
{[\mathrm{g}]}\end{array}$} & \multicolumn{2}{|c|}{$\begin{array}{l}\text { Mass of cap- } \\
\text { tured fragments }\end{array}$} & \multicolumn{5}{|c|}{$\begin{array}{l}\text { Mass of fragments } m_{c i}[\mathrm{~g}] \text { in the size } \\
\text { classes }\end{array}$} & \multirow{2}{*}{$F F_{E}$} \\
\hline & & & [g] & {$[\%]$} & $\begin{array}{c}<0.5 \\
\mathrm{~mm}\end{array}$ & $\begin{array}{c}0.5 \div 1 \\
\mathrm{~mm}\end{array}$ & $\begin{array}{l}1 \div 2 \\
\mathrm{~mm}\end{array}$ & $\begin{array}{l}2 \div 5 \\
\mathrm{~mm}\end{array}$ & $\begin{array}{l}>5 \\
\mathrm{~mm}\end{array}$ & \\
\hline $\begin{array}{l}\text { SB with Sin- } \\
\text { terfire bullet }\end{array}$ & 528 & 6.48 & 6.23 & 96 & 1.51 & 0.16 & 0.17 & 2.21 & 2.18 & 35 \\
\hline $\begin{array}{l}\text { Remington } \\
\text { Disintegrator }\end{array}$ & 407 & 6.58 & 5.52 & 84 & 3.99 & 0.08 & 0.19 & 0.59 & 0.67 & 65 \\
\hline $\begin{array}{c}\text { Experimental } \\
\text { SR }\end{array}$ & 454 & 5.16 & 4.18 & 81 & 2.56 & 0.24 & 0.36 & 0.50 & 0.52 & 63 \\
\hline
\end{tabular}

The results show that the bullet Disintegrator and SR had similar frangibility when hitting the steel plate of the thickness of $5 \mathrm{~mm}$. The bullet Sinterfire had a significantly lower value of frangibility (about half), even though it had a greater impact velocity. The bullet Sinterfire is therefore less capable to disintegrate when compared to the other evaluated bullets. The reason was, beside the difference of manufacturing technologies (high compaction pressure, sintering), the creation of a secondary fragment in a relatively deep cavity in the steel plate (Fig. 4). The greatest fragment of the bullet Sinterfire which was pressed in the cavity in the steel plate - secondary pressed part (number $5^{*}$ in Fig. 4), has the maximal diameter of $10.2 \mathrm{~mm}$. 

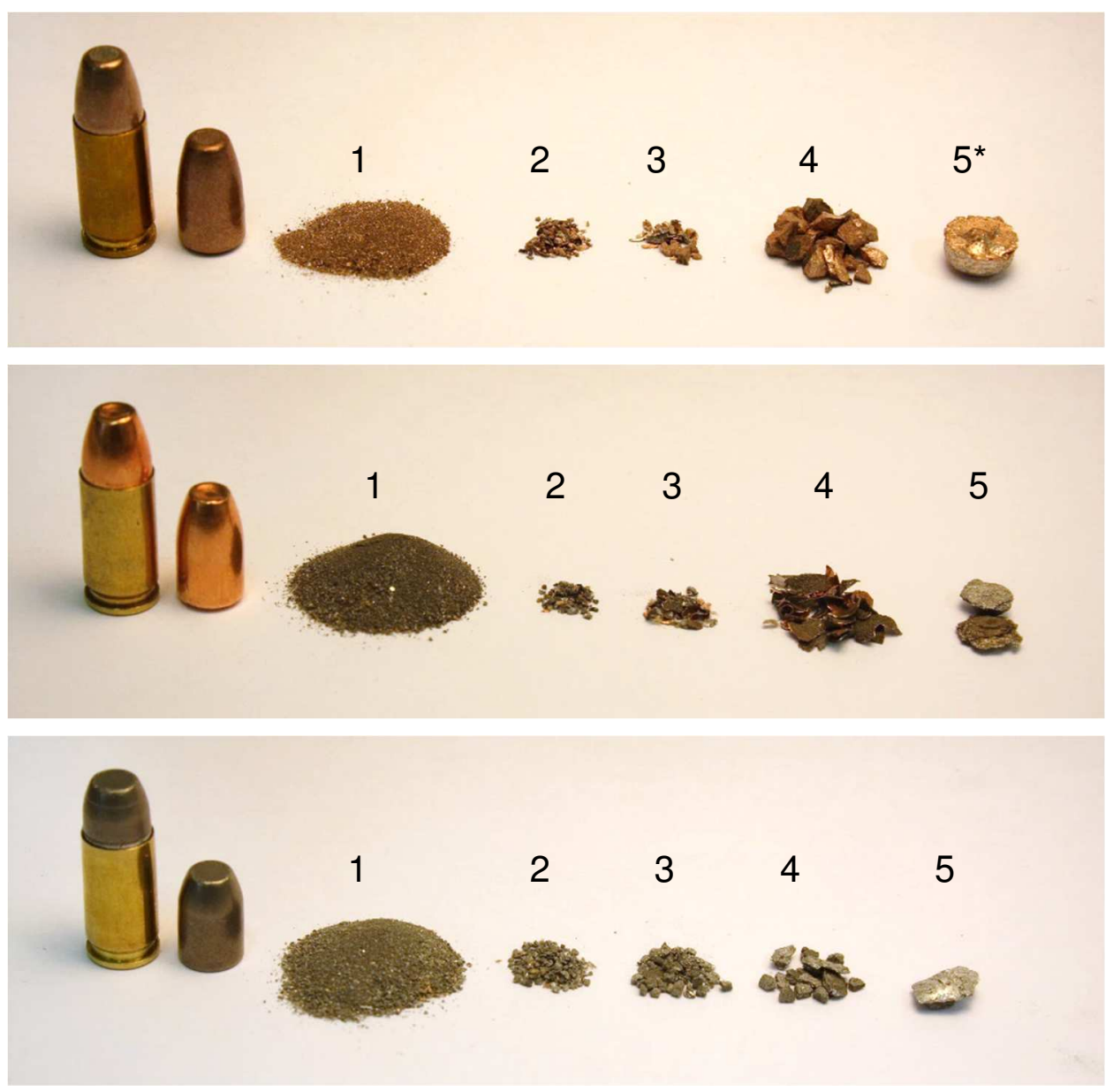

Fig. 4 Frangible cartridges, bullets and their fragments after hitting $5 \mathrm{~mm}$ steel plate (from top to bottom: Sinterfire, Disintegrator, SR; the numbers $1 \div 5$ indicate the size class of fragments of bullet)

\section{Conclusion}

Disintegration into fragments upon the impact with the defined target is a key feature of all frangible bullets. However, the process and results of disintegration of frangible bullets differ depending on many factors. In order to evaluate the fragmentation level of the bullet, it is necessary to have a suitable model for quantitative evaluation of the capability of bullet to disintegrate into fragments. In this article, the theoretical model and the experimental model have been presented, both based on the knowledge of the bullet's behaviour in terminal ballistics domain. In both models, the quantifier of frangibility is called the frangibility factor - the dimensionless parameter whose magnitude indicates the capability of bullet to disintegrate, and it increases with the increasing magnitude of the factor $F F$.

Quantification of frangibility of frangible bullet is crucial for the research and development of frangible ammunition. Experimental evaluation of frangibility based on 
fragments' size distribution by using results of shooting experiment is preferred in practice because it is easier to obtain and it seems to be more objective than theoretical evaluation based on the impact energy. The experimental results can be used in general to assess the capability to disintegrate frangible bullet in the entire range of damage from the start of disintegration into the large fragments to the complete disintegration of bullet into small particles.

The described model of frangibility evaluation in this article can be applied even for ultra-frangible bullets by the choice of a suitable standard target (target is made from block of material which substitutes the soft tissue). However, the analysis of fragments of frangible bullet dispersed in the soft tissue substitution blocks (ballistic gelatin, gels and soaps) remains problematic.

\section{References}

[1] MULLINS, J.F. Frangible ammunition: the new wave in firearms ammunition. Boulder: Paladin Press, 2001. ISBN 1-58160-267-7.

[2] RYDLO, M. Ballistic characteristics of frangible firearms ammunition (in Czech). Dissertation thesis. Brno: University of Defence, 2010.

[3] RYDLO, M. Theoretical Criterion for Evaluation of the Frangibility Factor. Advances in military technology. Brno, 2010, vol. 5, no. 2, p. 57-67. ISSN 1802-2308.

[4] ADAM, I. et. al. Research and Development of Testing Methods of Frangible Bullets for the Purposes of Legislative Classification (in Czech). Brno: Prototypa $\mathrm{ZM}, 2014$.

[5] Von KARMAN, T. and DUWEZ, P. The Propagation of Plastic Deformation in Solids. J. Appl. Phys., Vol. 21, 1950, p. 987-994.

[6] MELOUN, M. and MILITKÝ, J. Statistical Analysis of Experimental Data (in Czech). Praha: Academia, 2004. ISBN 80-200-1254-0.

[7] KAPLAN, J., KLOSE, R., FOSSUM, R. and DI MAIO, V.J.M. Centerfire Frangible Ammunition: Wounding Potential and Other Forensic Concerns. The American Journal of Forensic Medicine and Pathology. 1998, vol. 19, no. 4, p. 299-302. ISSN 0195-7910.

[8] KOMENDA, J. and RYDLO, M. Frangible Ammunition [study] (in Czech). Prague: Forensic Institute, 2011.

[9] KOMENDA, J. et al. The Evaluation Methodology of Piercing Effect of Firearms Ammunition: (version 4.0) (in Czech). Brno: University of Defence, 2008. ISBN 978-80-7231-309-9.

[10] POKORNÝ, Z. Construction and Function of Frangible Ammunition (in Czech). Master thesis. Brno: University of Defence, 2006.

[11] SCHYMA, C., BITTNER, M. and PLACIDI, P. The MEN Frangible - Study of a New Bullet in Gelatin. The American Journal of Forensic Medicine and Pathology. 1997, vol. 18, no. 4, p. 325-330. ISSN 0195-7910. 